\title{
3 Research Square

\section{Prognostic implications of hemophagocytic syndrome in CD5-positive diffuse large B cell lymphoma patients}

\section{Xue Bai}

First Affiliated Hospital of Shantou University Medical College

\section{Linwei Xu}

First Affiliated Hospital of Shantou University Medical College

\section{Yeshan Chen}

First Affiliated Hospital of Shantou University Medical College

Shaoze Lin

First Affiliated Hospital of Shantou University Medical College

\section{Xueyang Xing}

First Affiliated Hospital of Shantou University Medical College

\section{Yongzhong Su}

First Affiliated Hospital of Shantou University Medical College

Hongfang Tao ( $\nabla$ taohongfangchn@126.com )

First Affiliated Hospital of Shantou University Medical College

\section{Research Article}

Keywords: CD5, 19q13, central nervous system International Prognostic Index, lymphoma-associated hemophagocytic syndrome

Posted Date: January 27th, 2022

DOI: https://doi.org/10.21203/rs.3.rs-1242665/v1

License: (c) (1) This work is licensed under a Creative Commons Attribution 4.0 International License. Read Full License 


\section{Abstract}

\section{Materials and methods}

We retrospectively investigated $17 \mathrm{CD} 5^{+} \mathrm{DLBCL}$ and $85 \mathrm{CD} 5^{-} \mathrm{DLBCL}$ patients to compare their clinicopathologic features and prognosis under R-CHOP chemotherapy, then evaluate impact of HPS on the survival of whole DLBCL and CD5 $5^{+}$DLBCL subgroup.

\section{Results}

The $\mathrm{CD}^{+}$DLBCL cohort had advanced stage, frequent bone marrow involvement, HPS event and high central nervous system International Prognostic Index (CNS-IPI). With a median follow-up of 23.6 months (range, 0.03-155.8months), the estimated 2-year OS of $C D 5^{+}$group and $C D 5^{-}$group were $57.8 \%$ $(95 \% \mathrm{Cl}=33.9 \%-81.7 \%)$ and $72 \%(95 \% \mathrm{Cl}=58.7 \%-85.3 \%)$, respectively $(\mathrm{p}<0.05)$. The multivariate analysis of 102 cases of DLBCL demonstrated that the HPS event was an independent prognostic factor for PFS $(\mathrm{HR}=15.11,95 \% \mathrm{Cl}=0.97-235.05, \mathrm{p}=0.05)$. Within $\mathrm{CD} 5^{+} \mathrm{DLBCL}$ cohort, patients with HPS had a significant shorter PFS and OS than HPS-free group (median PFS, 0.43months VS 5.98 months, $p<0.05$; median OS, 0.69 months and not reached, respectively, $\mathrm{p}<0.05)$.

\section{Conclusion}

Our data identifies that CD5 is an unfavourable prognostic predictor of DLBCL, and HPS related to worse survival of $C D 5^{+}$DLBCL patients.

\section{Introduction}

Diffuse large B-cell lymphoma (DLBCL) is the most common B-cell non-Hodgkin's lymphoma and has heterogeneous biological properties. ${ }^{1}$ Approximately $60 \%$ cases of DLBCL can benefit from current frontline chemotherapy with rituximab (R-CHOP), while the remianing patients are still confronted with worse survival due to primary drug resistance or multiple relapses. ${ }^{2} \mathrm{CD} 5^{+} \mathrm{DLBCL}$ has gradually gained the attention for its unfavorable outcomes. ${ }^{3,4}$ Despite data of retrospective studies were heterogeneous, the consensus is that de novo $C D 5^{+} \mathrm{DLBCL}$ is associated with older age, female gender, extranodal disease at presentation, advanced stage, high IPI, high rates of CNS relapse, non-GCB subtype and Bcl-2 overexpression compared with $\mathrm{CD}^{-}{ }^{-} \mathrm{DLBCL}^{5-9}$

We noticed that the CD5 molecule on B lymphoma cell exhibit a particular proneness to HPS event at the course of disease progression. HPS, a rapidly deteriorating clinical course that is characterized by a severe hyperinflammatory condition resulting in histiocytic proliferation, prolonged fever, hepatosplenomegaly, cytopenia, hypertriglyceridemia, low fibrinogen, elevated ferritin and abnormal 
activity of certain cytokines. ${ }^{10} \mathrm{~A}$ recent study shown that the presence of HPS in lymphoma patients predicts poor prognosis and early death. ${ }^{11}$ To the best of our knowledge, there are only several cases of CD5 ${ }^{+}$DLBCL with hemophagocytic syndrome (HPS) have been reported. ${ }^{12-14}$ However, the implication of such adverse event on this population remains unknown. This is a first report on the prognostic implications of HPS on survival of $\mathrm{CD} 5^{+}$DLBCL.

The aims of this study were to investigate clinicopathologic features and determine the implications of HPS on survival of $\mathrm{CD} 5^{+}$DLBCL.

\section{Patients And Methods}

This study retrospectively included 102 DLBCL patients treated at The First Affiliated Hospital of Shantou University between February 2016 and June 2021 through medical records database.

\section{Diagnosis}

The pathological diagnosis of DLBCL was made according to the $2008 \mathrm{WHO}$ classification of malignant lymphoma. Standard of CD5-positive was defined by immunohistochemical (IHC) examination and/or flow cytometry. Cases with at least $10 \%$ of tumor cells expressing CD5 were considered positive. As a substitute, for patients who failed to perform IHC, CD5 expression was evaluated by flow cytometry of biopsy specimen. The cutoffs for positive CD10, MUM-1, Bcl-6, c-Myc, Bcl-2 and p53 results were at least $30 \%, 30 \%, 30 \%, 40 \%, 50 \%$ and $50 \%$ of lymphoma cell, respectively. The GCB/non-GCB subtype was determined by the result of CD10, Bcl-6 and MUM1.

\section{Treatment}

$95 \%$ of patients were treated with rituximab-containing chemotherapy at least 3 cycles, including first-line RCHOP (92\%), R-dose-adjusted-EPOCH (3\%), R-Gemox and (R)ICE which were the most commonly used salvage treatment regimens in relapsed and refractory patients ( 9 and 5 patients respectively). Furthermore, autologous stem cell transplant(auto-SCT) was performed in 2 patients who achieved complete remission (CR) after induced chemotherapy. In order to ameliorate the high CNS relapse, the routine 4-8 times intrathecal injection of methotrexate (MTX) and cytarabine, systemically chemotherapy with a high-dose of MTX were given to 8 patients with intermediate/high-risk CNS relapse. Given that poor outcome and high frequency of CNS relapse of patients with $\mathrm{CD}^{+}$, novel drugs, for instance, a selective BTK inhibitor-ibrutinib, bendamustine, lenalidomide, programmed cell death 1 (PD-1)/PD-L1 blockade and venetoclax alone or in combination were added to primary chemotherapy to induce $\mathrm{CR}$.

\section{Definitions of endpoints}

Treatment responses were assessed using computed tomography (CT) or positron emission tomographycomputed tomography (PET-CT) after the beginning of the 4-6 cycles of chemotherapy. CR was defined as all lesions disappeared confirmed by PET-CT/CT. Progressive disease (PD) was defined as PET 
negative or the maximum SPD of measurable lesions decreased $\geq 50 \%$. Relapse was defined as appearance of new lesions or increase in diameter of the original lesions $\geq 50 \%$ after previous negativity. Stable disease (SD) was defined as failure to achieve the above CR, PD or relapse. Progression-free survival (PFS) was calculated from the date of diagnosis to the date of disease progression, biopsyproven relapse, or death, whichever came first. Overall survival (OS) was calculated from the date of diagnosis to the date of death from any cause or follow-up deadline.

\section{Statistical analysis}

Differences between categorical data were assessed by the chi-square test. Both OS and PFS were analyzed by the Kaplan-Meier method and compared by log-rank tests. The influence of parameters on OS and PFS was analyzed using univariate or multivariate Cox regression. A $P$ value $<0.05$ was considered statistically significant. All statistical analyses were finished using the IBM SPSS Statistics 23.0 software.

\section{Ethical approval}

The study was approved by the institutional review board of The First Affiliated Hospital of Shantou University Medical College in accordance with the Declaration of Helsinki. Written informed consent was obtained from all patients before hospitalization.

\section{Results}

\section{Clinicopathologic characteristics}

In the enrolled DLBCL patients, $17(16.6 \%)$ were $\mathrm{CD}^{+}$and $85(83.4 \%)$ were CD5- The median age at diagnosis in the $\mathrm{CD}^{+}$group was 64 (range $25-80$ ) years; $64.7 \%(n=11)$ were male. There was no significant difference between the two groups in age or sex distribution. Compared with CD5-DLBCL cohort, $C D 5^{+}$DLBCL cohort exhibited a particular proneness to advanced stage, BM involvement $\triangle \mathrm{HPS}$ event and high CNS-IPI score $(P<0.05)$. Moreover, the $\mathrm{CD}^{+}$group was more frequently with $\mathrm{B}$-symptoms, higher probability of $>1$ ECOG PS, higher level of LDH and IPI score (Table 1). With regard to de novo extranodal site involved, the most common site of extranodal disease was gastrointestinal tract $48.5 \%$ (34/70) followed by bone or bone marrow $35.7 \%$ (25/70), other affected sites including pharyngeal lymphatic loop (4/70), adrenal (4/70), kidney (3/70), skin (3/70), lung (3/70), testis (2/70), breast (2/70), CNS (2/70), liver (2/70), pancreas (2/70), bladder (3/70) and thyroid $(1 / 70)$.

Immunohistologically, the $\mathrm{Bcl}-2$ positive rate was much higher in the $\mathrm{CD} 5^{+} \mathrm{DLBCL}$ group than that in the CD5־ DLBCL group (94.1\% VS 82.4\%, $p>0.05$ ). Likewise, non-GCB subtype, Bcl-6, Myc and doubleexpressing were easily seen in $C D 5^{+}$DLBCL group. Interestingly, current studies have shown that p53 expressed in $48.1 \%$ CD5 DLBCL, while no one case was found to show p53-positive in $\mathrm{CD}^{+}$DLBCL. Quantitative of EBV was available in 45 of all patients who underwent EBV loading testing. And the result 
of EBV infection between the CD5 $5^{+}$DLBCL (10\%) and CD5- DLBCL groups (14.3\%) was similar. Genetically, detection of chromosomal was available for 24 DLBCL cases $(23.5 \%, 24 / 102$ cases) by using G-banding from the BM. The 19q13 chromosomal aberration was easier found in CD $5^{+}$cases $(1 / 6 \mathrm{VS}$ 1/18).

\section{Outcomes and survival stratified by CNS relapsed risk groups and HPS event}

With rituximab-containing chemotherapy, $C D 5^{+}$DLBCL patients had significantly worse PFS than CD5 DLBCL patients (median, 1.08 months vs 14.95 months, $p=0.037$, Figure $1 \mathrm{~A}$ ). The median OS for $\mathrm{CD} 5^{+}$ and $\mathrm{CD}^{-}$patients were not reached, but the mean OS were $35.68(95 \% \mathrm{Cl} 21.53-49.82)$ months and 95.62 (95\% Cl=69.35-121.89) months respectively $\left(\mathrm{p}=0.053\right.$, Figure 1B). The estimated 2-year PFS of $\mathrm{CD}^{+}$ group and $\mathrm{CD}^{-}$group were not reached and $24.4 \%$ (95\% Cl=2.7\%-46.1\%), respectively $(p<0.05)$. Consistently, the estimated 2-year OS of $\mathrm{CD}^{+}$group and $\mathrm{CD}^{-}$group were $57.8 \%(95 \% \mathrm{Cl}=33.9 \%-81.7 \%)$ and $72 \%(95 \% \mathrm{Cl}=58.7 \%-85.3 \%)$, respectively $(p<0.05)$.

None of the CD5+ cases in our study experienced CNS relapse. Notably, patients divided into high-risk CNS relapse of $\mathrm{CD}^{+}$cohort were significantly frequent than those in $\mathrm{CD} 5^{-}$cohort $(52.9 \%$ VS $16.5 \%$, $\mathrm{p}<0.05$, Table 1). In terms of all DLBCL patients survival冈the median PFS for the low-, intermediate- and high-risk CNS relapsed group were 7.03 (95\% Cl 6.89-7.17) months, 22.05 (95\% Cl 11.49-32.60) months and 4.63 (95\% $\mathrm{Cl} 0.00-10.64)$ months respectively ( $\mathrm{p}=0.006$, Figure $2 \mathrm{~A})$. And the median OS for the low-, intermediate- and high-risk CNS relapsed group were not reached, $62.32(95 \% \mathrm{Cl} 6.57-118.07)$ months and 25.43 (95\% Cl 0.00-59.08) months respectively ( $p=0.001$, Figure 2B).

For the entire DLBCL group, the difference in OS and PFS between HPS and HPS-free group was statistically significant. Patients with HPS had a significant shorter PFS than HPS-free group (0.43months VS 14.23 months, $p<0.001$, Figure $3 A$ ). Patients suffered with HPS event had a significant shorter OS compared with patients who failed to (median OS, 8.17 months and not reached and respectively, $\mathrm{p}=0.001$, Figure 3B). Similarly, for $C D 5^{+} \mathrm{DLBCL}$ subgroup, patients underwent HPS event had a significant shorter OS compared with patients who did not (median OS, 0.69 months and not reached, respectively, $p<0.05$, Figure 3 C). Patients with HPS was associated with inferior PFS compared with HPSfree group (median PFS, 0.43months VS 5.98 months, $p<0.05$, Figure 3D).

\section{Prognostic factors}

Baseline characteristics were analyzed for their association with outcomes. In univariate analysis of 102 cases DLBCL, shorter PFS was associated with $\mathrm{CD}^{-}$positive ( $\left.\mathrm{HR}=2.58,95 \% \mathrm{Cl}=1.02-6.55, p=0.04\right), \mathrm{HPS}$ event $(\mathrm{HR}=28.95,95 \% \mathrm{Cl}=4.66-179.6, p<0.001)$ and high $\mathrm{CNS}-\mathrm{IPI}$ subgroup $(\mathrm{HR}=3.61,95 \% \mathrm{Cl}=1.45-9.03$, $p=0.005)$. Multivariate analysis of clinicopathologic factors including age, sex, stage, B symptoms, extranodal sites, PS and IPI score, COO, expression of BCL-2 and CD5, BM involvement and HPS event confirmed that the HPS suffering $(\mathrm{HR}=15.11,95 \% \mathrm{Cl}=0.97-235.05)$ independently predicted poor PFS in $\operatorname{DLBCL}(p=0.05)$ (Table 2). Shorter OS was associated with PS $>1 \quad(\mathrm{HR}=2.92,95 \% \mathrm{Cl}=1.27-6.71$, 
$p=0.01), \mathrm{IPI}>2(\mathrm{HR}=2.70,95 \% \mathrm{Cl}=1.07-6.88, p=0.03)$, HPS suffering $(\mathrm{HR}=6.40,95 \% \mathrm{Cl}=1.75-23.38, p=0.005)$ and high CNS-IPI $(\mathrm{HR}=4.08,95 \% \mathrm{Cl}=1.79-9.30, p<0.001)$ score (Table 3). However, no factor in our 102 series was identified as independent adverse prognostic factor for OS (Table 3 ).

Within $\mathrm{CD}^{+}$DLBCL group, shorter OS was associated with PS $>1 \quad(\mathrm{HR}=10.23,95 \% \mathrm{Cl}=1.022-85.68, p=0.03)$ and HPS event $(\mathrm{HR}=4.95,95 \% \mathrm{Cl}=1.07-22.90, p=0.04)$ (Figure 4). For PFS, inferior survival was associated with female $(\mathrm{HR}=10.76,95 \% \mathrm{Cl}=1.08-106.30, \mathrm{p}=0.04), \mathrm{PS}>1(\mathrm{HR}=8.51,95 \% \mathrm{Cl}=0.99-73.03, p=0.05)$ and HPS event (HR=13.54, 95\% Cl=1.36-135.2, $p=0.02$ ) (Figure 5). No adverse factor was observed to independently influence both PFS and OS. Additionally, there was no statistically significant difference in CR rate between the CD5+ group and CD5- group (56.4\% and $66.7 \%$, respectively, $p=0.512)$. Likewise, there was no significant difference in CD5 status for cases with PD $(22.2 \%$ VS $34.5 \%, p=0.706)$ and relapse $(11.1 \%$ VS $9.1 \%, p=1.000)$.

\section{Discussion}

Recently, it has been increasingly recognized that patients with DLBCL express CD5 antigen follows an aggressive clinical course, and the response to therapy is unsatisfactory, with a median survival of less than 3 years. $4,5,15$

Studies on CD5-positive DLBCL are mainly from Japan, and epidemiological information shown that the disease accounts for about 5-22\% of all DLBCL. ${ }^{5}$ Our study identified 17 (16.6\%) CD5 ${ }^{+}$DLBCL patients, higher frequency than some domestic research centers, but is compatible with Japanese data. And such high incidence could be explained by the routine clinical testing of CD5 antigen before treatment and more cases with $C D 5^{+}$DLBCL were confirmed by flow cytometry. /Results of clinical information suggested that these patients exhibit more invasive with higher frequency of BM involvement and highrisk of CNS relapse. Similarly, previous studies have suggested that $C D 5^{+}$DLBCL is predominant in the elderly ( $>60$ years old) and female populations (female : male ratio $>1),{ }^{4,9}$ possesses a higher probability of $P S>1,|P|>2$, non-GCB subtype and overexpression of Bcl-2, higher LDH level as well as high tendency to develop B symptoms. ${ }^{8}$ Meanwhile, this disease found to be involved in more than one extranodal site (26\%-45\%) when diagnosed, among which BM (28\%) and CNS (13\%) are the most frequent sites of involvement. ${ }^{16}$

Additionally, chromosomal analysis of this study found that 19q13 chromosomal aberration was detected more frequent than that in the $C D 5^{-} D L B C L$ group within evaluabled CD5-expressing

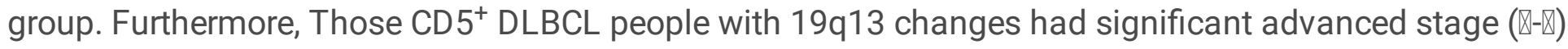
with high IPI and CNS-IPI score. And they experienced PD during R-CHOP or relapse after CR. This finding was in line with recent reports in DLBCL patients, which suggested that the aberration of 19q13 in chromosomes is related to poor prognosis with event-free survival was less than 24 months. ${ }^{17,18}$ Therefore, our findings emphasize the importance of routine chromosomal examination in this patient group, especially for those were divided into the high-risk group according to IPI system. 
One of the unique pictures is that patients with $\mathrm{CD} 5^{+}$had significantly higher CNS-IPI than those who did not express CD5. It has been known that CNS-IPI is a robust, highly reproducible tool that can be used to estimate the risk of CNS relapse or progression in patients with DLBCL treated with R-CHOP chemotherapy. ${ }^{19}$ Mutiple studies have observed that a high incidence (12.7-23\%) of CNS relapse in CD5+ DLBCL. ${ }^{3,4}$ Moreover, others also reported that the CNS disease strongly affected the OS of CD5+ DLBCL. ${ }^{3 \text {, }}$ ${ }^{4}$ Likewise, the univariate survival analysis of our $\mathrm{CD}^{+}$cohort indicated that both inferior PFS and OS were associated with high CNS-IPI score. Interestingly, no case was confirmed CNS relapse in our study, this may attribute to routine prophylactic strategies plus novel drugs such as ibrutinib, bendamustine and lenalidomide, which have demonstrated durable efficiency for primary central nervous system lymphoma. ${ }^{20}$

Another notable finding in the present study was that patients diagnosed as $C D 5^{+}$DLBCL experienced HPS event more frequently than its counterpart. Lymphoma-associated hemophagocytic syndrome (LAHS) are common seen in T cell or natural killer cell lymphoma, whereas LAHS secondary to B cell lymphoma is quite rare. Survival analysis stratified by HPS of CD5 $5^{+}$DLBCL demonstrated that patients with HPS event had inferior survival than those without. Also, univariate analysis revealed that shorter PFS and OS were correlated with HPS suffering for both entire DLBCL and the subgroup divided by CD5 signature. It's worth noting that these patients in real word tend to be too frial to survival from such severe hit, so most of them underwent early deaths after diagnosis. This current work confirmed the negetive role of HPS on survival of both DLBCL and CD5-postitive subgroup. As the number of CD5+ DLBCL patients in this study is limited, a larger group and longer follow-up are required further to test its significance.

The mechanisms of CD5 that drive the inferior outcomes of DLBCL have not been fully elucidated. The potential mechanisms accepted currently are classified into two pathways. One pathway includes the inhibition of BCR signaling, which is regarded as the CD5-mediated BCR-dependent pathway via mediating tumoral escape by immunoreceptor tyrosine-based inhibition motif (ITIM) and SHP-1 (SrC homology 2 [SH2] domaine containing protein tyrosine phosphatase 1) recruitment. ${ }^{21-23}$ The other pathway involves the overexpression of interleukin (IL)-10, Bcl-2, cyclin D2, and CXCR4 (C-X-C motif chemokine receptor 4), which are regarded as the CD5-mediated BCR-independent pathway. However, which pathway acts as dominant contributor is unclear, but disease-associated inflammatory storm evidenced by hemophagocytosis seems to offer indirect explanation for the latter theory.

\section{Conclusion}

In summary, our work proved that CD5 is an unfavourable prognostic maker of DLBCL with advancedstage disease tending to higher frequency of BM involvement and high-risk of CNS relapse. More importantly, HPS enhances this negative effect further.

Hence, it is crucial to assessed CD5 in all newly diagnosed cases of DLBCL because of its poor survival. Importantly, attention should be paid to HPS on prognosis evaluation of DLBCL in addition to general 
clinical materials, especially for those with CD5 positive. Finally, further clinical trials are required to improve survival of this subset of patients with DLBCL.

\section{Declarations}

\section{Founding}

This research did not receive any specific grant from funding agencies in the public, commercial, or notfor-profit sectors.

\section{Conflict of Interest Statement}

The authors declare that they have no known competing financial interests or personal relationships that could have appeared to influence the work reported in this paper. And this manuscript has been approved by all authors for publication.

\section{Data availability}

All data that support the findings of this study are available in the supplementary information file.

\section{Acknowledgments}

We would like to show our deepest gratitude to Professor Liang-li Hong

and the pathologists involved in for diagnosis of $\mathrm{CD} 5^{+} \mathrm{DLBCL}$.

\section{Author contributions}

Xue bai collected and analyzed the data and wrote the manuscript. Linwei Xu and Yeshan Chen assisted in collecting data and drawing diagrams. Shaoze Lin and Xueyang Xing assisted in analyzing the data. Yongzhong Su assisted in editing the manuscript. Hongfang Tao designed the project and revised the manuscript.

\section{References}

1. Sehn LH, Gascoyne RD. Diffuse large B-cell lymphoma: optimizing outcome in the context of clinical and biologic heterogeneity. Blood 2015; 125: 22-32.

2. Li S, Young KH, Medeiros LJ. Diffuse large B-cell lymphoma. Pathology 2018; 50: 74-87.

3. Hu B, Nastoupil LJ, Loghavi S et al. De novo CD5+ diffuse large B-cell lymphoma, NOS: clinical characteristics and outcomes in rituximab era. Leuk Lymphoma 2020; 61: 328-336.

4. Miyazaki K, Yamaguchi M, Suzuki R et al. CD5-positive diffuse large B-cell lymphoma: a retrospective study in 337 patients treated by chemotherapy with or without rituximab. Ann Oncol 2011; 22: 16011607. 
5. Xu-Monette ZY, Tu M, Jabbar KJ et al. Clinical and biological significance of de novo CD5+ diffuse large B-cell lymphoma in Western countries. Oncotarget 2015; 6: 5615-5633.

6. Chuang WY, Chang H, Shih LY et al. CD5 positivity is an independent adverse prognostic factor in elderly patients with diffuse large B cell lymphoma. Virchows Arch 2015; 467: 571-582.

7. Tang $\mathrm{H}$, Zhou $\mathrm{H}$, Wei $\mathrm{J}$ et al. Clinicopathologic significance and therapeutic implication of de novo CD5+ diffuse large B-cell lymphoma. Hematology 2019; 24: 446-454.

8. Niitsu N, Okamoto M, Tamaru Jl et al. Clinicopathologic characteristics and treatment outcome of the addition of rituximab to chemotherapy for CD5-positive in comparison with CD5-negative diffuse large B-cell lymphoma. Ann Oncol 2010; 21: 2069-2074.

9. Yamaguchi $M$, Seto $M$, Okamoto $M$ et al. De novo CD5+ diffuse large B-cell lymphoma: a clinicopathologic study of 109 patients. Blood 2002; 99: 815-821.

10. Han AR, Lee HR, Park BB et al. Lymphoma-associated hemophagocytic syndrome: clinical features and treatment outcome. Ann Hematol 2007; 86: 493-498.

11. Sun SR, Wu M, Wulipan F et al. Clinical features and treatment outcome of patients with nonHodgkin lymphoma-associated hemophagocytic lymphohistiocytosis. Zhonghua Xue Ye Xue Za Zhi 2021; 42: 324-331.

12. Rodriguez I, Grau J, Sancho JM, Ribera JM. Diffuse large B cell lymphoma associated with hemophagocytic syndrome. Med Clin (Barc) 2011; 136: 87-88.

13. Davidson-Moncada JK, McDuffee E, Roschewski M. CD5+ diffuse large B-cell lymphoma with hemophagocytosis. J Clin Oncol 2013; 31: e76-79.

14. Schram AM, Berliner N. How I treat hemophagocytic lymphohistiocytosis in the adult patient. Blood 2015; 125: 2908-2914.

15. Jain P, Fayad LE, Rosenwald A et al. Recent advances in de novo CD5+ diffuse large B cell lymphoma. Am J Hematol 2013; 88: 798-802.

16. Yamaguchi M, Nakamura N, Suzuki R et al. De novo CD5+ diffuse large B-cell lymphoma: results of a detailed clinicopathological review in 120 patients. Haematologica 2008; 93: 1195-1202.

17. Mishima $Y$, Terui $Y$, Yokoyama $M$ et al. Bearing $19 q 13$ aberration predicts poor prognosis in nongerminal centre type of CD5(+) DLBCL. Br J Haematol 2018; 183: 661-664.

18. Novak AJ, Asmann YW, Maurer MJ et al. Whole-exome analysis reveals novel somatic genomic alterations associated with outcome in immunochemotherapy-treated diffuse large B-cell lymphoma. Blood Cancer J 2015; 5: e346.

19. Schmitz N, Zeynalova S, Nickelsen M et al. CNS International Prognostic Index: A Risk Model for CNS Relapse in Patients With Diffuse Large B-Cell Lymphoma Treated With R-CHOP. J Clin Oncol 2016; 34: 3150-3156.

20. Illerhaus G, Schorb E, Kasenda B. Novel agents for primary central nervous system lymphoma: evidence and perspectives. Blood 2018; 132: 681-688. 
21. Kurosaki T, Maeda A, Ishiai M et al. Regulation of the phospholipase C-gamma2 pathway in $B$ cells. Immunol Rev 2000; 176: 19-29.

22. Rothstein TL. Signals and susceptibility to programmed death in b cells. Curr Opin Immunol 1996; 8 : 362-371.

23. Gary-Gouy H, Harriague J, Dalloul A et al. CD5-negative regulation of B cell receptor signaling pathways originates from tyrosine residue Y429 outside an immunoreceptor tyrosine-based inhibitory motif. J Immunol 2002; 168: 232-239.

\section{Tables}

Table 1. Patients' characteristics at diagnosis. 


\begin{tabular}{|c|c|c|c|}
\hline variables & CD5+DLBCL N(\%) & CD5-DLBCL N(\%) & $p$ value \\
\hline Age,years & & & 0.717 \\
\hline Median (range) & $64(25-80)$ & $63(24-87)$ & \\
\hline$<60$ & $6(35.3)$ & $34(40.0)$ & \\
\hline$\geqq 60$ & $11(64.7)$ & $51(60.0)$ & \\
\hline Sex & & & 0.422 \\
\hline Male & $11(64.7)$ & $46(54.1)$ & \\
\hline Female & $6(35.3)$ & $39(45.9)$ & \\
\hline Stage & & & 0.031 \\
\hline$\bigotimes-\bigotimes$ & $3(17.6)$ & $39(45.9)$ & \\
\hline 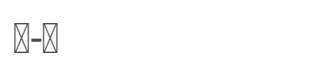 & $14(82.4)$ & $46(54.1)$ & \\
\hline B symptoms & & & 0.330 \\
\hline No & $7(41.2)$ & $46(54.1)$ & \\
\hline Yes & $10(58.8)$ & $39(45.9)$ & \\
\hline ECOG PS & & & 0.156 \\
\hline $0-1$ & $9(52.9)$ & $60(70.6)$ & \\
\hline$>1$ & $8(47.1)$ & $25(29.4)$ & \\
\hline Serum LDH level & & & 0.113 \\
\hline Normal & $3(17.6)$ & $32(37.6)$ & \\
\hline Elevated & $14(82.4)$ & $53(62.4)$ & \\
\hline Extranodal sites & & & 0.776 \\
\hline Yes & $12(70.6)$ & $57(67.1)$ & \\
\hline No & $5(29.4)$ & $28(32.9)$ & \\
\hline Extranodal sites & & & 1.000 \\
\hline $0-1$ & $14(82.4)$ & $70(82.4)$ & \\
\hline$>1$ & $3(17.6)$ & $15(17.6)$ & \\
\hline IPI score & & & 0.535 \\
\hline $0-2$ & $7(41.2)$ & $42(49.4)$ & \\
\hline $3-5$ & 10(58.8) & $43(50.6)$ & \\
\hline
\end{tabular}




\begin{tabular}{|c|c|c|c|}
\hline \multicolumn{3}{|l|}{ Cell of origin } & \multirow[t]{2}{*}{0.519} \\
\hline GCB & $5(29.4)$ & $32(37.6)$ & \\
\hline Non-GCB & 12(70.6) & $53(62.4)$ & \\
\hline \multicolumn{4}{|c|}{ Immunohistochemistry } \\
\hline Bcl6+N=99 & 13(81.3) & 64(77.1) & 1.000 \\
\hline$B c \mid 2+N=102$ & 16(94.1) & $70(82.4)$ & 0.298 \\
\hline Myc+ N=89 & $6(42.9)$ & $26(34.7)$ & 0.558 \\
\hline DEL N=89 & $6(42.9)$ & $25(33.3)$ & 0.548 \\
\hline $\mathrm{p} 53+\mathrm{N}=32$ & $0(0)$ & $13(48.1)$ & 0.064 \\
\hline EBV infection* & & & 1.000 \\
\hline Yes & $1(10)$ & $5(14.3)$ & \\
\hline No & $9(90)$ & $30(85.7)$ & \\
\hline BM involvement & & & 0.043 \\
\hline No & $10(58.8)$ & $71(83.5)$ & \\
\hline Yes & $7(41.2)$ & 14(16.5) & \\
\hline HPS occurrence & & & 0.007 \\
\hline No & $13(76.5)$ & $83(97.6)$ & \\
\hline Yes & $4(23.5)$ & $2(2.4)$ & \\
\hline CNS-IPI score & & & 0.005 \\
\hline 0-1/Low & $3(17.7)$ & $27(31.7)$ & \\
\hline 2-3/Intermediate & $5(29.4)$ & $44(51.8)$ & \\
\hline 4-6/High & $9(52.9)$ & $14(16.5)$ & \\
\hline 19q13aberration & & & 0.446 \\
\hline $\mathrm{N}=24$ & $N=6$ & $N=18$ & \\
\hline No & $5(83.3)$ & $17(94.4)$ & \\
\hline Yes & $1(16.7)$ & $1(5.6)$ & \\
\hline
\end{tabular}

Abbreviations: ECOG PS = Eastern Cooperative Oncology Group performance status; $\mathrm{LDH}=$ lactate dehydrogenase; IPI = International Prognostic Index; GCB = germinal center B-cell-like; $\mathrm{BM}$ = bone marrow; HPS = hemophagocytic syndrome; CNS = central nervous system; DE = double-expressing, defined as $\mathrm{Myc}+$ and Bcl2+; * Assessed by quantatitve of whole bood. 
Table 2. Correlation analysis of PFS in the overall DLBCL patients.

\begin{tabular}{|c|c|c|c|c|c|c|}
\hline \multirow[t]{2}{*}{ variables } & \multicolumn{3}{|c|}{ univariate analysis } & \multicolumn{3}{|c|}{ multivariate analysis } \\
\hline & $H R$ & $95 \% \mathrm{Cl}$ & $P$ & $\mathrm{HR}$ & $95 \% \mathrm{Cl}$ & $P$ \\
\hline Age $\geq 60$ years & 1.29 & $0.50-3.35$ & 0.59 & 1.29 & $0.25-6.52$ & 0.75 \\
\hline Female & 1.15 & $0.49-2.68$ & 0.73 & 0.75 & $0.18-3.02$ & 0.68 \\
\hline Stage $\otimes-\otimes$ & 1.08 & $0.40-2.94$ & 0.87 & 0.31 & $0.03-2.66$ & 0.28 \\
\hline B symptoms & 1.49 & $0.62-3.57$ & 0.37 & 1.00 & $0.24-4.00$ & 0.99 \\
\hline ECOG PS $>1$ & 1.91 & $0.81-4.51$ & 0.13 & 1.12 & $0.14-8.63$ & 0.91 \\
\hline Serum LDH >ELN & 1.34 & $0.30-6.08$ & 0.70 & 0.20 & $0.03-1.50$ & 0.11 \\
\hline Extranodal sites $>1$ & 1.46 & $0.59-3.61$ & 0.40 & 1.96 & $0.27-14.31$ & 0.50 \\
\hline IPI score $\geqq 3$ & 1.00 & $0.39-2.58$ & 1.00 & 0.44 & $0.02-11.31$ & 0.62 \\
\hline Non-GCB by Han's & 1.32 & $0.53-3.31$ & 0.54 & 1.29 & $0.30-5.57$ & 0.73 \\
\hline $\mathrm{Bcl} 2+$ by $\mathrm{IHC}$ & 1.06 & $0.36-3.17$ & 0.90 & 0.38 & $0.08-1.78$ & 0.22 \\
\hline CD5+ & 2.58 & $1.02-6.55$ & 0.04 & 2.80 & $0.51-15.34$ & 0.23 \\
\hline BM involvement & 1.28 & $0.52-3.15$ & 0.59 & 0.39 & $0.07-2.37$ & 0.31 \\
\hline HPS event & 28.95 & $4.66-179.6$ & $<0.001$ & 15.11 & $0.97-235.05$ & 0.05 \\
\hline High CNS IPI score & 3.61 & $1.45-9.03$ & 0.005 & 12.24 & $0.87-172.24$ & 0.06 \\
\hline
\end{tabular}

Table 3. Univariate and multivariate Cox hazard analysis of risk factors for OS in the overall DLBCL patients. 


\begin{tabular}{|c|c|c|c|c|c|c|}
\hline \multirow[t]{2}{*}{ variables } & \multicolumn{3}{|c|}{ univariate analysis } & \multicolumn{3}{|c|}{ multivariate analysis } \\
\hline & $\mathrm{HR}$ & $95 \% \mathrm{Cl}$ & $P$ & HR & $95 \% \mathrm{Cl}$ & $P$ \\
\hline Age $>60$ years & 2.33 & $0.91-5.99$ & 0.07 & 1.60 & $0.38-6.79$ & 0.52 \\
\hline Female & 0.90 & $0.39-2.10$ & 0.82 & 1.64 & $0.62-4.36$ & 0.32 \\
\hline 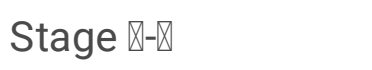 & 2.20 & $0.81-5.99$ & 0.12 & 0.96 & $0.20-4.62$ & 0.96 \\
\hline B symptoms & 2.12 & $0.88-5.13$ & 0.09 & 1.52 & $0.45-5.12$ & 0.49 \\
\hline ECOG PS $>1$ & 2.92 & $1.27-6.71$ & 0.01 & 1.21 & $0.31-4.84$ & 0.78 \\
\hline Serum LDH >ELN & 2.01 & $0.74-5.47$ & 0.17 & 0.95 & $0.27-3.35$ & 0.93 \\
\hline Extranodal sites $>1$ & 2.18 & $0.87-5.41$ & 0.09 & 1.80 & $0.41-7.90$ & 0.43 \\
\hline $\mid \mathrm{PI} \geqq 3$ & 2.70 & $1.07-6.88$ & 0.03 & 1.16 & $0.19-6.95$ & 0.86 \\
\hline Non-GCB by Han's & 1.30 & $0.53-3.20$ & 0.56 & 1.13 & $0.38-3.40$ & 0.82 \\
\hline $\mathrm{Bcl} 2+$ by $\mathrm{IHC}$ & 1.03 & $0.35-3.06$ & 0.94 & 1.17 & $0.33-4.20$ & 0.81 \\
\hline CD5+ & 2.24 & $0.91-5.52$ & 0.07 & 2.01 & $0.54-7.56$ & 0.30 \\
\hline BM involvement & 1.74 & $0.74-4.12$ & 0.20 & 0.61 & $0.18-2.12$ & 0.44 \\
\hline HPS event & 6.40 & $1.75-23.38$ & 0.005 & 2.69 & $0.48-15.27$ & 0.26 \\
\hline High CNS-IPI score & 4.08 & $1.79-9.30$ & $<0.001$ & 2.12 & $0.42-10.79$ & 0.36 \\
\hline
\end{tabular}

\section{Figures}

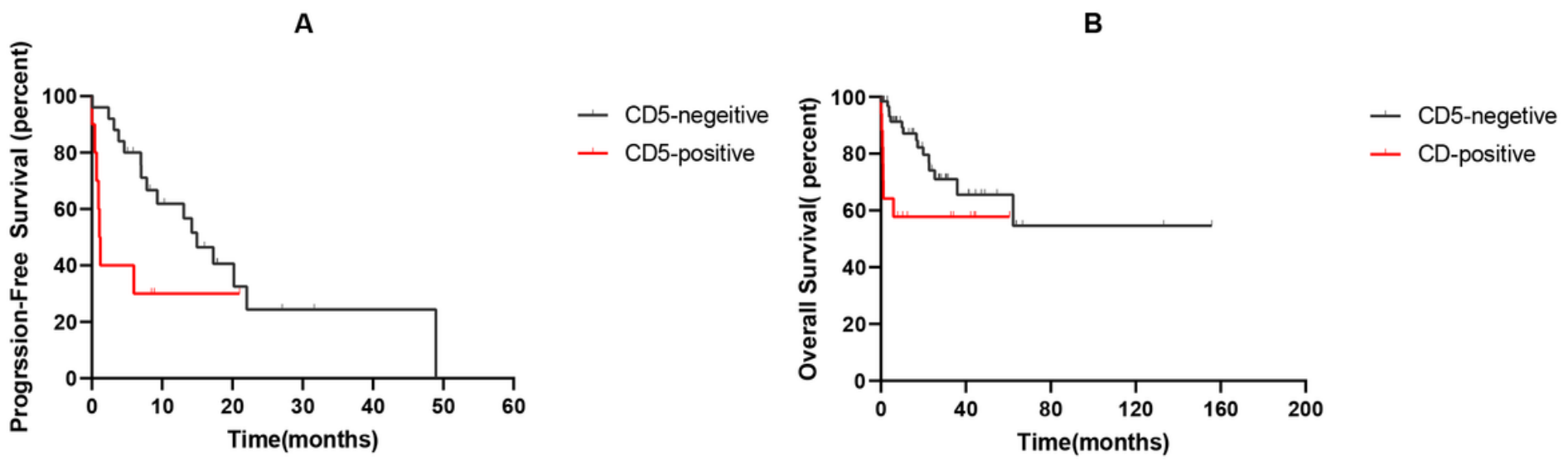

Figure 1

Legend not included with this version 

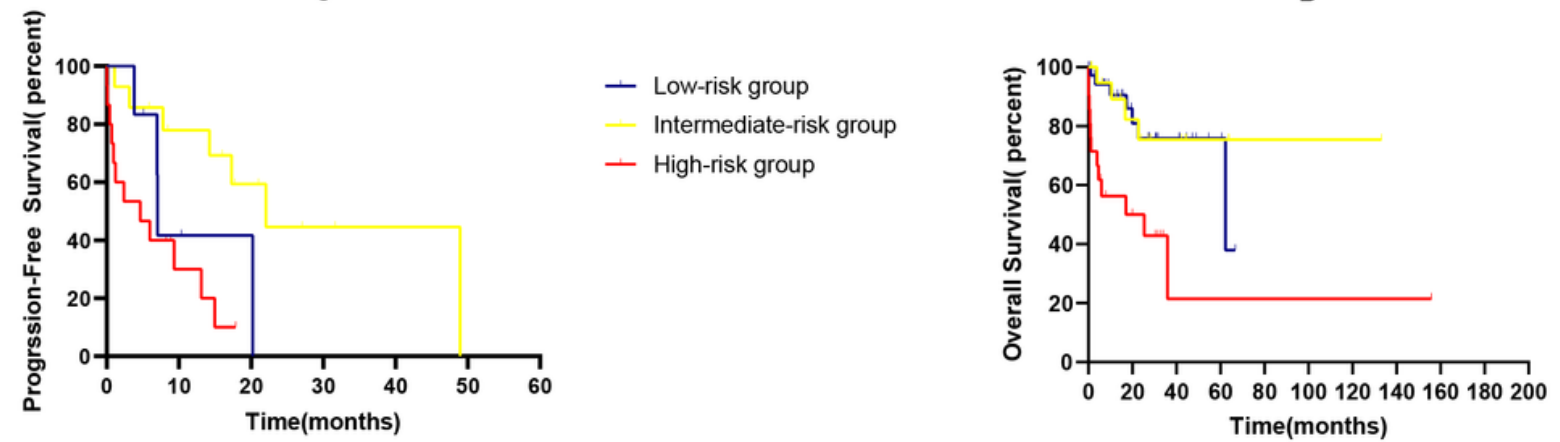

$\begin{array}{ll} & \text { Low-risk group } \\ \text { — Intermediate-risk group } & \\ + & \text { High-risk group }\end{array}$

Figure 2

Legend not included with this version 

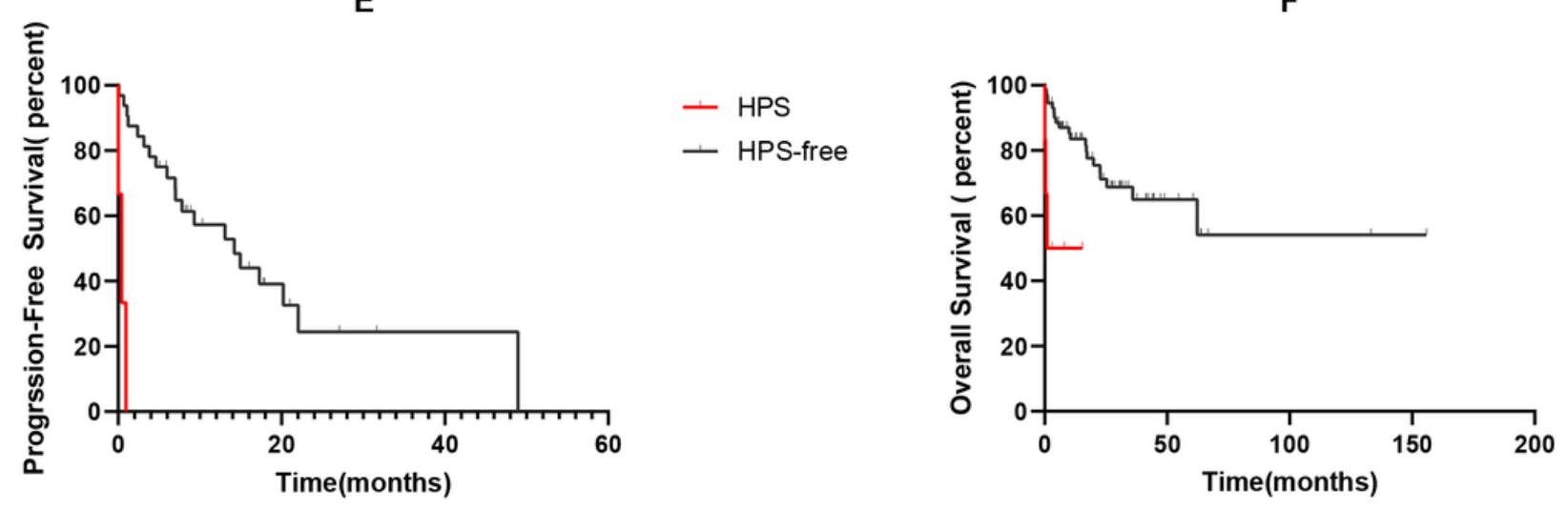

- HPS

- HPS-free

G

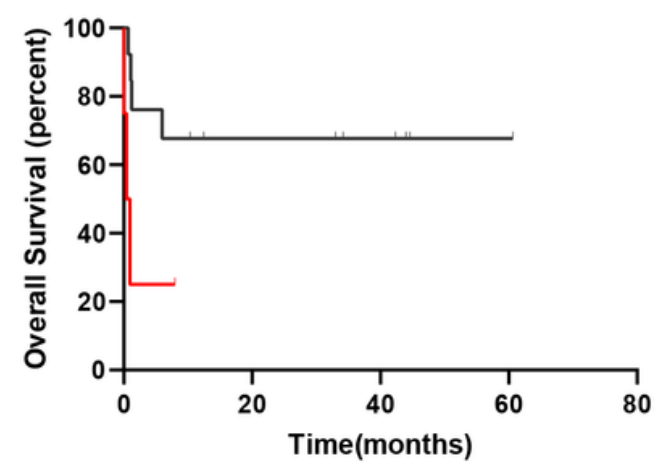

- HPS

- HPS-free

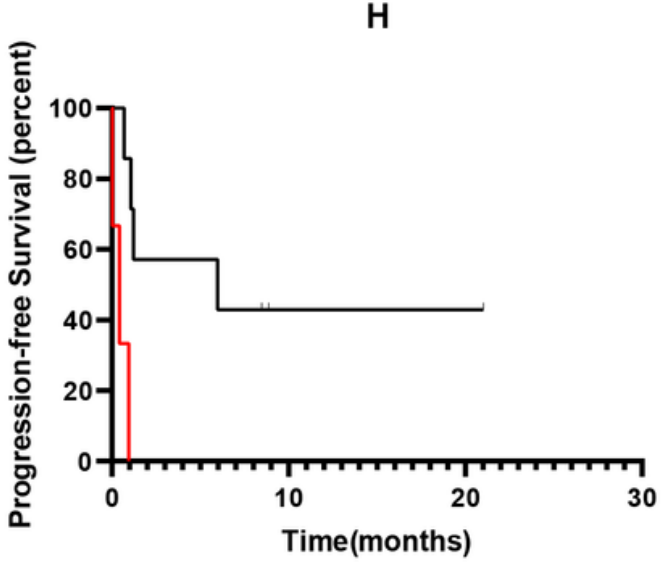

Figure 3

Legend not included with this version 


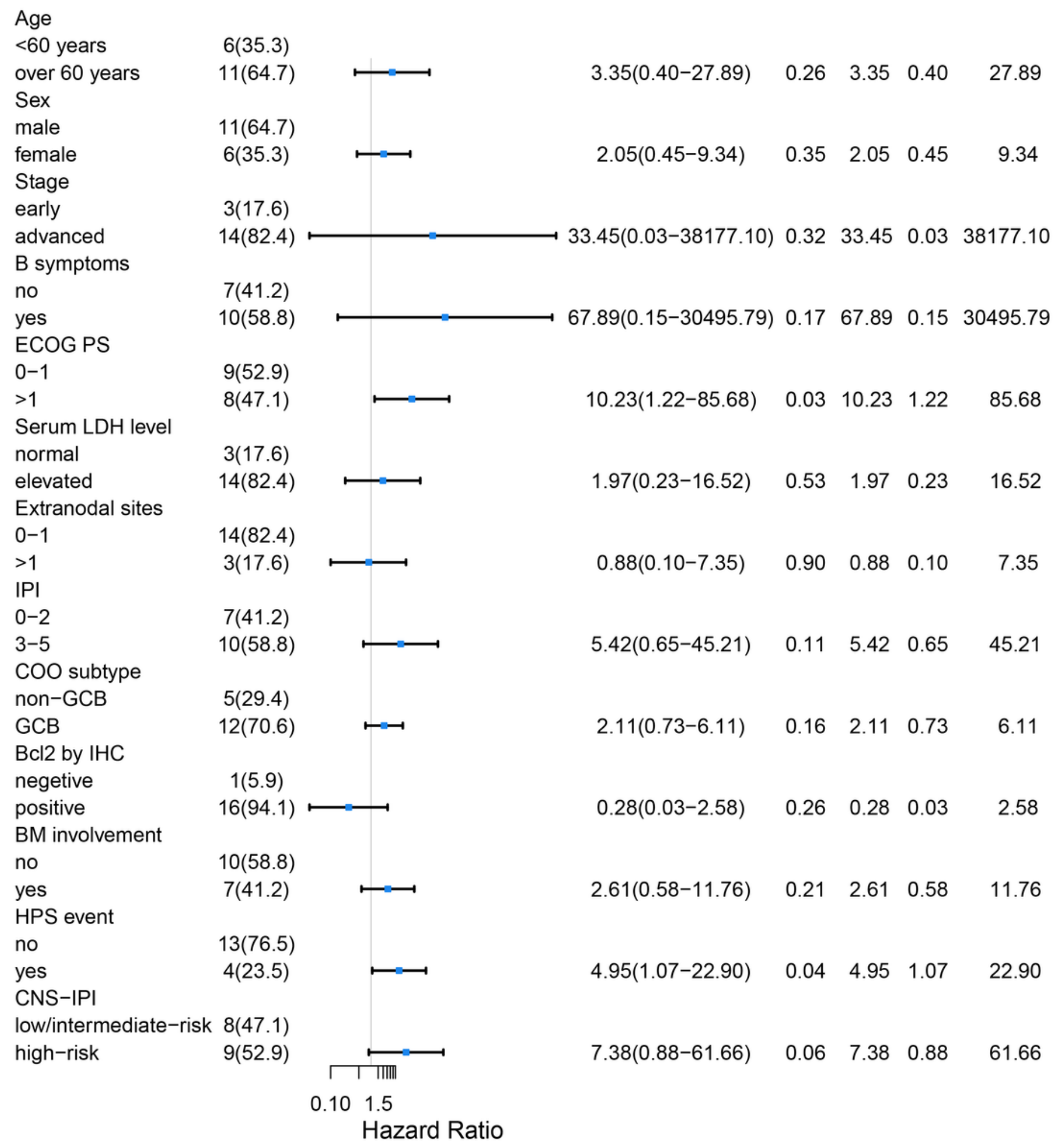

Figure 4

Legend not included with this version 


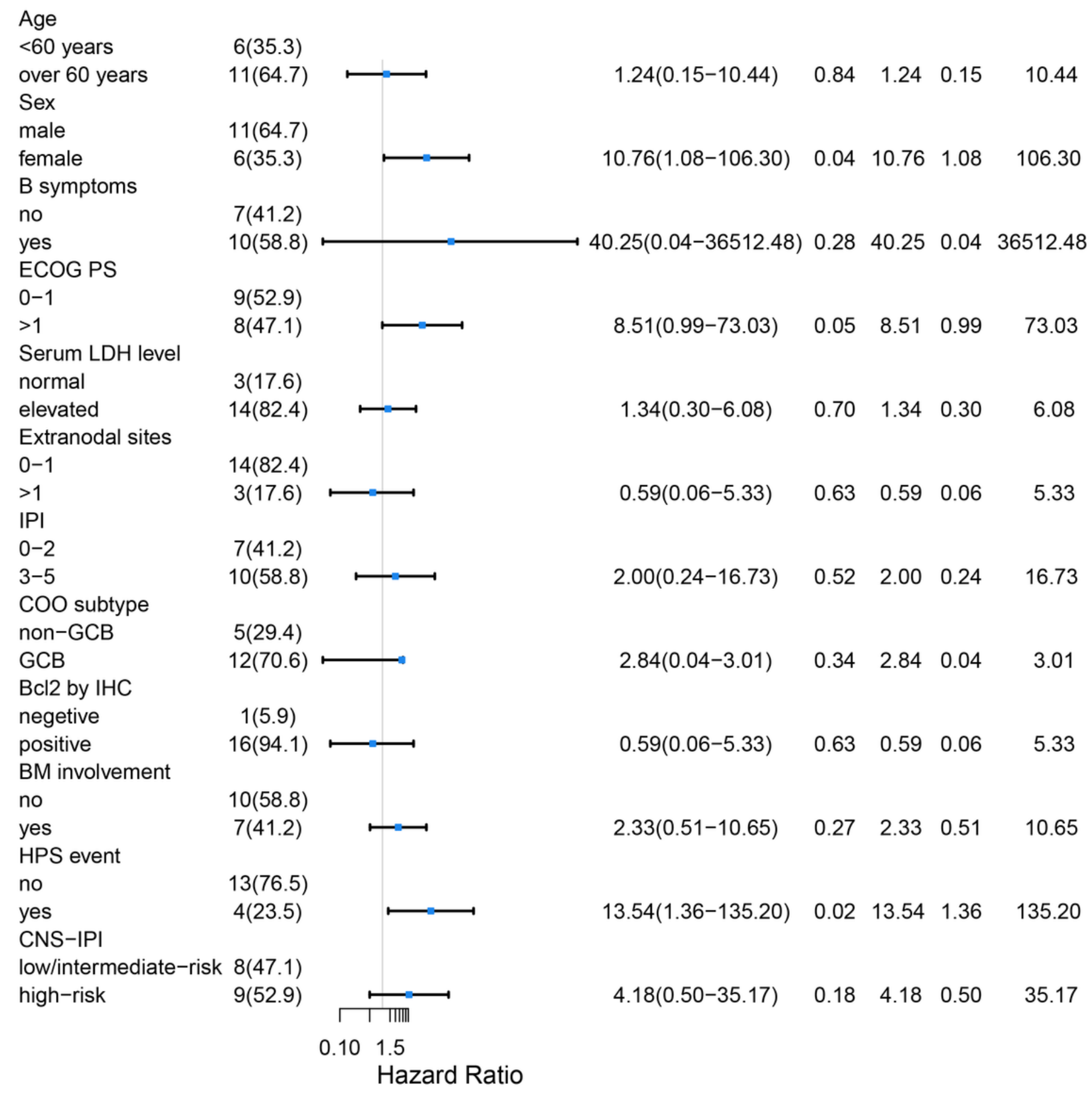

Figure 5

Legend not included with this version

\section{Supplementary Files}

This is a list of supplementary files associated with this preprint. Click to download.

- Supplementarydata.sav 